\title{
UNDERSTANDING MARKET ORIENTATION AMONG SMALL BUSINESSES IN RURAL GHANA
}

\author{
Blankson, Charles, University of North Texas, United States of America \\ Cowan, Kirsten, University of North Texas, United States of America \\ Tran, Trang, University of North Texas, United States of America
}

\begin{abstract}
The challenges imposed by developing and emerging markets in marketing strategy formulation have long been the concern of marketing scholars (Kotler 2000; Schultz 2006). Some countries in the region, such as Ghana, are making strides toward more democratic governance (Whitfield 2005). While the Ghanaian marketplace is a potentially fruitful research domain it is also no doubt challenging. While review of the extant literature reveals an increasing interest in the adoption of market orientation concepts for managerial application in sub-Saharan African market settings, the small business domain appears overlooked. To that end, the purpose of this paper is to assess the patterns of market orientation within the small business sector in rural Ghana and thus makes a contribution to the marketing literature.

The researchers conducted a pilot study involving covert observation techniques (see Stafford and Stafford 1993; Gill and Johnson 1997; Omar 1997) and face-to-face interviews, with a convenience sample of ten small businesses. The observation involved monitoring the activities of small businesses including customer care/service, pricing tactics, distribution, marketing communications, and product/service quality (see also Appiah-Adu 1998). The data were transcribed and content coded to reveal the underlying themes (Goodwin et al. 1997). Through the interview and observations, it appears customer care is a top priority. Rural small businesses in Ghana are also employee-oriented. While no formal research is conducted in these small businesses, they do continually solicit feedback, provide value and anticipate needs, which underlies the philosophy of market orientation, according to Gray and Hooley (2002).
\end{abstract}

References available upon request. 